\title{
Phenomenology and Ontology of Language and Expression: Merleau-Ponty on Speaking and Spoken Speech
}

Hayden Kee

Fordham University

January 2018

\section{Abstract}

This paper clarifies Merleau-Ponty's distinction between speaking and spoken speech, and the relation between the two, in his Phenomenology of Perception. Against a common interpretation, I argue on exegetical and philosophical grounds that the distinction should not be understood as one between two kinds of speech, but rather between two internally related dimensions present in all speech. This suggests an interdependence between speaking and spoken aspects of speech, and some commentators have critiqued Merleau-Ponty for claiming a priority of speaking over spoken speech. However, there is a sense in which Merleau-Ponty is right to emphasize the priority, namely, in terms of the ontological priority of the speaking subject with respect to language understood as a constituted cultural ideality. The latter only maintains its ontological status insofar as it is taken up by a language community. I favorably contrast Merleau-Ponty's views on this question to those of the late Heidegger and de Saussure, and suggest potential applications of this clarified position for contemporary discussions in philosophy of language.

Keywords: Merleau-Ponty, Phenomenology of Perception, Expression, Language, Speech

Acknowledgments: I would like to express my gratitude to Jennifer Gosetti-Ferencei and to a reviewer from Human Studies for feedback on earlier versions of this paper. 


\section{Introduction}

The distinction between speaking speech and spoken speech is central to Merleau-Ponty's discussions of language and expression throughout his oeuvre, reappearing in various guises and with varying terminologies at different periods of his philosophical development. As a first approximation, it is a distinction between the aspect of speech that constitutes meaning and that aspect that relies upon already constituted meanings. However, Merleau-Ponty nowhere presents a sustained exposition of the topic, his various treatments are often ambiguous, and it is not clear that a coherent position emerges from them. This has led some commentators to mischaracterize the distinction and the relation between the terms distinguished, producing a skewed picture of the scope of the phenomena described and their significance for Merleau-Ponty's overall view on language and expression.

In this paper, I attempt to clarify Merleau-Ponty's views on this topic in his most comprehensive and complete work, Phenomenology of Perception. ${ }^{1}$ First, the nature of the distinction itself must be established. I argue that, contrary to one common interpretation, supported by some of MerleauPonty's own less precise pronouncements on the issue, the distinction between speaking and spoken speech should be understood as a distinction between moments, aspects, or dimensions of all speech, rather than between two distinct kinds of speech. With the nature of the original distinction clarified, and this further distinction in place, we can specify the relationships of priority and interdependence between the two. As some commentators have suggested, all speaking speech operates within a context of spoken speech, and thus there is a relation of interdependence between the two moments. However, I argue that there is another respect in which speaking speech is primary, namely, it is ontologically primary with respect to language understood as a cultural ideality, insofar as the latter is only possible on the basis of the former. This follows from Merleau-Ponty's insistence on the centrality of the speaking subject in any approach to language. I conclude by discussing this feature of his thought on language through a comparison with Saussure and the later Heidegger, highlighting the uniqueness and importance of Merleau-Ponty's views for contemporary philosophy of language.

\section{Speech, Language, and Expression in Phenomenology of Perception}

Merleau-Ponty introduces the distinction between speaking speech and spoken speech in the final chapter of Part I of the Phenomenology of Perception. Part I provides a phenomenology of the living body as the nexus of all perception, action, and meaning for the existential subject. The final chapter, "The body as speech and expression," ${ }^{2}$ explores these themes from the perspective of the speaking subject, and, somewhat more ambitiously, builds a case for reinserting the speaking subject into the center of the science and philosophy of language. In order to situate the discussion of speaking and spoken speech, my primary interest in this paper, I will first introduce Merleau-Ponty's central claims concerning the nature of the speaking subject, language, and expression. This is especially important

\footnotetext{
${ }^{1}$ Restricting the focus to Phenomenology of Perception allows us best to see how this distinction interlocks with other central themes in Merleau-Ponty's thought. The distinction established there is retained, with modifications, throughout later writings. Further, as we shall see, illuminating his position on this topic in Phenomenology of Perception has consequences for interpretive debates about precisely when the notion of expression comes to maturity in Merleau-Ponty's thought.

${ }^{2}$ Merleau-Ponty, Phenomenology of Perception (Merleau-Ponty 1976, 213ff.; 2012, 179ff.). Henceforth cited as PhP, followed by the French and English page number. E.g., "PhP 184/149."
} 
since, although Merleau-Ponty's discussion of speaking and spoken speech spreads throughout the chapter, and indeed the book, it never receives a concentrated elaboration. As it is not my intention to defend Merleau-Ponty's general theory of speech, expression, and language, a brief expository sketch will suffice here.

First, we must understand Merleau-Ponty's unique account of the phenomenon of expression. ${ }^{3}$ Expression - for example, in the form of speech - is not the mere putting-into-words of a thought that was already complete and self-contained independently of its being expressed. The linguistic expression is not like clothing cast over the body of thought (PhP 222/187, 448/408), or like an external vehicle that merely serves to convey thought from one mind to another. Rather, for Merleau-Ponty, expression is constitutive of the very thought it accomplishes and the meaning it communicates. There is an internal relation between the act of expression and the thought or signification that comes to expression through it. This is why inchoate thought always tends towards expression, and why finding the magic word can suddenly dispel the vague mists of confusion and impart lucidity (PhP 216f./182f.). The experience to which Merleau-Ponty is directing our attention here is familiar to writers and artists, who express themselves not so much to communicate the achievements of their thought or imagination, but rather to carry out the work of thought and imagination in the first place. It is this interface between expression and the already-expressed that will concern us below when we turn to the relation between speaking and spoken speech.

Merleau-Ponty's conception of expression must be distinguished from Husserl's account of the expressive function (Ausdrucksfunktion) of the sign in the First Logical Investigation (Husserl 2001) and his other early works of static phenomenology. In the Investigations, the sign's expressive function signifies (bedeutet) an already constituted, ideal, objective meaning. Hence in Ideas I, Husserl emphasizes that the act of expression is not productive of meaning, but rather that its contribution is exhausted in bringing to expression a signification that has already been established (Husserl 1982, $\S 124,294 \mathrm{ff}$.). As we will see, this already-constituted aspect of speech is precisely what Merleau-Ponty opposes to originary expression. ${ }^{4}$

\footnotetext{
${ }^{3}$ There is a growing literature discussing this crucial concept in Merleau-Ponty's thought. See Barbaras 2004; Fóti 2013; Hass 2008; Landes 2013.

${ }^{4}$ A detailed discussion of Husserl's influence on Merleau-Ponty and the latter's appropriation of the former is beyond the scope of the present effort. The following brief comment must suffice. Merleau-Ponty saw himself as taking up the work of the later Husserl, and he was perhaps more familiar with the vast corpus of Husserl's unpublished late manuscripts than anyone else working outside of Germany and Belgium in his generation. In the late works, especially the research in generative phenomenology, Husserl begins to develop an appreciation of how ideal meanings are constituted temporally through traditions that are founded by original acts of expression and institution (Stiftung). The ideal meanings correspond roughly and in part to what Merleau-Ponty will call "spoken speech," the original acts to "speaking speech." See especially "The Origin of Geometry," in Husserl 1970. From a developmental and genetic phenomenological perspective (about which I will have more to say below), Husserl, in a late text from 1935, begins to approach the Merleau-Pontian insight into the primacy of bodily expression, writing that "the first and simplest expression [Ausdruck] is that of bodily appearance as human body [leiblichen Aussehens als Menschenleib]." Human bodies are taken as "expressions of the existence [Dasein] of persons" (Husserl 1973, 665). Cf. PhP 204/169: "We might say that the body is the 'hidden form of self-being,' or, reciprocally, that personal existence is the taking up and the manifestation of a being in a given situation. If we therefore say that the body continuously expresses existence, then this is intended in the sense that speech expresses thought. [...] The body expresses total existence in this way, not that it is an external accompaniment of it, but because existence accomplishes itself in the body. This embodied sense is the central phenomenon of which
} 
Thus, for Merleau-Ponty, there is no thought or meaning that obtains independently of its expression. This of course does not entail that we aren't capable of a sort of sub-verbal thinking in words, "the conversation the soul has with itself," as Plato put it. ${ }^{5}$ Indeed, it is the ubiquity of this phenomenon, Merleau-Ponty thinks, that makes it so easy for us to overlook the constituting achievement of expression. However, this sort of thought, even if it is the more common phenomenon, has a secondary status. It is only because preceding acts of expression have been laid down in our perceptual, cognitive, and linguistic landscape and outfitted with established meanings that we can operate silently with already-expressed thoughts. Here the ubiquity and utility of the secondary operation is precisely what conceals from us the originary achievement of the creative act of expressing, which thus effaces itself in its own expressed product (PhP 223/188f.). This movement is analogous to the one by which the constituting, genetic achievement of perception is forgotten in favor of a world of constituted perceptual objects, or the way for Heidegger the disclosure of being is forgotten in our immersion in the beings disclosed.

Merleau-Ponty suggests at times that the various modes of expression are all on an equal footing ( $\mathrm{PhP}$ 451/411). However, given the role of the living body as the locus of all meaning (PhP 183/148) and condition of possibility of all expressive operations (Php 448/408) in Phenomenology of Perception, a case can be made for the primacy of bodily gesture in expression. In the chapter on the body, speech, and expression, Merleau-Ponty advances a gestural approach to speech and language. Here gesture is understood in a liberal sense, including facial expression and other bodily manifestations of emotion, referential gestures such as emblems and ostension, and even the style that a person expresses through their general demeanor and comportment. The meaning of these gestures is not to be found in some concealed realm of inner thought or feeling that I infer or simulate on the basis of the external observation of a human body. Rather, the meaning is given immediately, manifestly and expressly, in the gesture itself. I see the anger itself in the scowl and clenched fists, and I see the referential intention itself in the outstretched index finger. I can read the meaning of the gesture in the body of the other because we both live a comparable embodiment. There is thus a reciprocity between my bodily gesture and the intention or emotion that animates it, on the one hand, and the gesture of another with its intention and emotion, on the other (PhP 225/190f.).

Just as there is an internal relation between a gesture and its meaning, so too between the spoken word and its meaning. This is not merely a matter of analogy, but rather of a thorough continuity between the most basic level of bodily expression and the higher orders of verbal communication that are established on its basis. Speech is a continuation and elaboration of bodily expression. By the same token, the thought and meaning expressed in speech is a development of more fundamental modes of embodied experience and worldly engagement. A pointing gesture picks out some aspect of our shared perceptual world, and a verbal gesture picks out some aspect of a shared cultural world that has emerged and been cultivated on the basis of the shared perceptual world (PhP 227/192). Indeed, perception itself, as Merleau-Ponty is at pains to detail throughout his corpus, is a creative, enactive

\footnotetext{
body and mind, or sign and signification are abstract moments." For an interpretation of Husserl's views on speech and language that moves Husserl much closer to a genetic, Merleau-Pontian view, see Welton 1983. On MerleauPonty's reading of Husserl, see the essay "The Philosopher and His Shadow" in Merleau-Ponty 1964, and the collection of essays on the topic gathered in Toadvine and Embree 2002.

${ }^{5}$ Plato, Theaetetus, 189e.
} 
process, one worthy of being called "primordial expression." ${ }^{6}$ There is continuity between, and inextricable entanglement of, the thinking and speaking subject with the embodied, perceiving, and acting subject. Correlatively, speech, language, and the domain of linguistic meaning must be understood on the basis of the perceiving, embodied subject and its existential involvements in the lifeworld. As Merleau-Ponty will later put it, "speech takes flight from where it rolls in the wave of speechless communication" (Merleau-Ponty 1964b, 17).

\section{Speaking and Spoken Speech}

It is in the context of this chapter of Phenomenology of Perception, presenting Merleau-Ponty's embodied, expressive approach to speech and language, that Merleau-Ponty introduces the distinction between speaking and spoken speech. It is a distinction that has been prefigured already in the work, and that will return throughout it. ${ }^{7}$ Thus it is somewhat curious that when Merleau-Ponty explicitly identifies it for the first time, he does so in a footnote, and that he presents what appears to amount to the same distinction using inconsistent terminology elsewhere in Phenomenology of Perception. We have, on the one hand, speaking speech (parole parlante), variously referred to as "originary speech" (PhP 218/530, 449/409), "authentic speech" (PhP 217/530, 451/411), and even "transcendental speech" (PhP 451/411). This is speech that is truly expressive in the sense discussed above, giving birth to new meaning. In it, "unformulated sense not only finds the means of conveying itself on the outside, but moreover acquires existence for itself, and is truly created as sense." ${ }^{8}$ On the other hand, there is spoken speech (parole parlée), also referred to as "secondary expression" (PhP 217/530), "empirical language" (PhP 218/530), "instituted" or "constituted speech" (PhP 224/189). Spoken speech involves the sedimented meanings that have accreted from previous acts of speaking speech, which lay down systems of constituted vocabulary and syntax (PhP 238/202).

Though his terminology varies, Merleau-Ponty does not indicate that he has anything beyond the one central distinction in mind. As we will see presently, the introduction of further distinctions can help us make sense out of these protean notions and the nature of the relations between them. Before further characterizing these relationships, however, and so as to avoid presupposing anything about them, let us first focus on the nature of the distinction itself. Merleau-Ponty first explicitly states it as follows:

\footnotetext{
${ }^{6}$ This statement comes from a later work (Merleau-Ponty 1964b, 67). But, already in PhP, Merleau-Ponty asserts that we witness "the miracle of expression" in the natural thing - the object of perception - before we experience it in other people (PhP 375/333). He describes the way the thing bears its meaning in much the same way he describes how a word or a gesture bears its: "We understand the thing as we understand a new behavior, that is, not through an intellectual operation of subsumption, but rather by taking up for ourselves the mode of existence that the observable signs sketch out before us. [...] The thing's sense inhabits it as the soul inhabits the body: it is not behind appearances. The sense of the ashtray [...] animates the ashtray, and it is quite evidently embodied in it. This is why we say that in perception the thing is given to us 'in person,' or 'in flesh and blood.' Prior to other persons, the thing accomplishes this miracle of expression: an interior that is revealed on the outside, a signification that descends into the world and begins to exist there and that can only be fully understood by attempting to see it there, in its place" (PhP 375f./333f.). See also PhP 58/35ff. For discussion of the respect in which perception is primordial expression already in PhP, see Landes 2013, 80ff. ${ }^{7}$ Cf. PhP 163/131f., 175-183/141-148, 204/169, 213-241/179-205, 264/227, 448-453/406-413, 461-466/422-466. ${ }^{8} \mathrm{PhP} 238 / 202$ - translation modified.
} 
Of course, there are reasons to distinguish between an authentic speech, which formulates for the first time, and a secondary expression, a speech about speech [une parole sur des paroles] that makes up the general run of empirical language. Only the first is identical with thought. ${ }^{9}$

In a note on the following page, he adds,

Once again, what we say here only applies to originary speech - that of the child who utters his first word, of the lover who discovers his emotion, of the "first man who spoke," or of the writer and the philosopher who awaken a primordial experience beneath traditions. (PhP 218/530)

The first statement is somewhat puzzling, especially as both English-language translations have rendered "une parole sur des paroles" as "speech about speech." ${ }^{10}$ This gives the impression that secondary speech (spoken speech) is a sort of metalanguage that we use to talk about speech, or that it designates that subset of isolable speech events - the subset of speech acts ${ }^{11}$, perhaps - that are about speech itself. If this were the best way of rendering Merleau-Ponty's text, Baldwin would be right to lament that this is a very unfortunate way of first presenting the distinction between speaking and spoken speech (Baldwin 2007, 91). Further, Merleau-Ponty would appear to be quite mistaken in holding that the "general run [l'ordinaire] of empirical language," the bulk of our everyday speech, is "speech about speech." Indeed, the very efficacy and utility of speech, as Merleau-Ponty himself often reminds us, consists in its self-effacing nature, in the fact that our words do not generally direct us to further words, but to the world. Additionally, if the distinction is taken to be mutually exclusive, it excludes the possibility of speech about speech itself being speaking speech, that is, genuinely expressive speech that brings about new meaning. But original philosophical work on language, such as Plato's Cratylus or Merleau-Ponty's own works on the topic, make a strong claim to being uses of language that are both "about speech" and also genuinely expressive and creative of new meaning.

There is, however, another translational and exegetical option here. Secondary expression, "une parole sur des paroles," could be understood as speech that is carried out upon (sur), or on the basis of, preceding acts of speech. It is "second-order expression" insofar as it takes its meaning from a background and basis of speech that has already occurred and already constituted a domain of established meanings. This translation, I believe, aligns better exegetically with what Merleau-Ponty has to say on these topics elsewhere in Phenomenology of Perception. ${ }^{12}$ However, even with this alteration, the text still lends itself to being interpreted as introducing a distinction between two kinds of speech event. Merleau-Ponty quantifies "the" authentic speech (une parole authentique) of the child, the lover, the philosopher, the writer, and the first nomothete. He suggests there is some identifiable "first time" for the formulation of a meaning. And he juxtaposes such speech to $a$ secondary speech and "the general run of empirical language." Thus Baldwin insists that a distinction between types of speech is

\footnotetext{
9 PhP 217f./530 - translation modified.

${ }^{10}$ Merleau-Ponty 2012, 530; 2002, 207.

11 I will generally refer to speech, considered as isolable units of whatever size and structure (individual gestures, words, sentences, utterances, works, etc.), as speech events, rather than speech acts, to avoid any confusion with speech act theory, though much of what I have to say about approaches that begin with a fundamental distinction between types of speech event would apply to speech act theory as well.

${ }^{12}$ At PhP 231/196 and 452/412, Merleau-Ponty uses the expression "parler sur la parole" in the context of discussions of reiteration and sedimentation in speech, i.e., speech on the basis of speech, not speech about speech.
} 
precisely what Merleau-Ponty has in mind (Baldwin 2007, 93, 95). And Inkpin, after cautiously introducing speaking and spoken speech somewhat more indeterminately as two "modes" of speech, eventually agrees that this is a distinction of kind. While Inkpin sees the discussions of speaking speech as shedding light on "certain kinds of language use," Merleau-Ponty ultimately overstates the importance of speaking speech - which Inkpin equates with speech that generates new meaning - and its supposed priority over spoken speech (Inkpin 2016, 110).

If the distinction is indeed meant to be one between kinds of speech act, Merleau-Ponty's position appears to be thoroughly untenable, for reasons I will discuss in the following section. However, first there is another question we must address, one concerning which Phenomenology of Perception is conspicuously ambiguous: If speaking speech is speech that constitutes meaning, for whom is the meaning thereby constituted? If we consider the four examples Merleau-Ponty offered us in the second passage quoted above with this question in mind, we find that we are dealing with a rather motley array of examples. The child speaking its first word is acquiring meanings that have already been laid down in the conventions of the language it is acquiring. They are new for it, but not new absolutely. We don't generally think of the process of language acquisition as being formative for the meaning of terms in the language as such. Similarly, the lover who gives articulation to his feeling through naming it is achieving new insight into his own inner life. With it, his understanding of the nature of love, and his understanding of the meaning of the word "love," is transforming. But we would not generally say that he is making a formative contribution to the meaning of the word "love" in the language at large. On first blush, then, it seems that in the case of both the child and the lover, the speaking speech is "speaking" only with respect to their personal idiolects, and not with respect to the shared, intersubjective domain of meaning. By contrast, the first word of the nomothete is not merely an achievement that will condition her individual understanding and usage henceforth. Rather, insofar as her creative achievement institutes a new shared pattern of usage and meaning, it lays down spoken speech for the language community at large. So too, the works of great philosophers and writers are formative of meaning for the language at large (and sometimes even for an interlinguistic intellectual community) and shape our collective understanding of ourselves and the world.

We find, then, that we must transversally intersect our original distinction with another: there is a speaking speech for an individual (speech that is formative for me personally) and a speaking speech for the language community at large (speech that changes the way we speak, think, and experience); and, by the same token, there is a spoken speech for an individual (that individual's acquired idiolect) and a spoken speech for the language community at large (the publicly available system of constituted vocabulary and syntax). Though Merleau-Ponty discusses examples that concern all four categories and their relations, he does not explicitly acknowledge the two-fold nature of the distinction between speaking and spoken speech in Phenomenology of Perception.

Before returning to my argument, a couple of observations concerning our now two-fold distinction are in order.

First, note that I do not actually have to be the one speaking for an act of expression to amount to speaking speech for me. In acquiring language, a child's understanding of the world around it and the meanings of words are informed as much, perhaps even more so, by the expressive activity of others and their interactions with the world as they are by the child's own speech. In reading a poem in earnest, my understanding of the language and the world is changing along with the poet's. Indeed, we 
can imagine an accidental poet who inadvertently introduces an innovation into shared spoken speech when some fragments from his grocery list were scavenged in a subway car by an editor from an avant garde literary magazine and published as found art. Similarly, my understanding of love and "love" is informed as much by Hollywood and advertisement as it is by my personal experiences of love. Even my understanding of my self is ultimately informed as much by what others say about me as by what I say about myself. As Merleau-Ponty will observe later, in some cases, "it is the same thing to speak to and to be spoken to" (Merleau-Ponty 1973b, 112).

Second, though it remains to be determined whether all four categories are on equal footing, we can at least say at this point that the relations between these four categories are internal. My acquired idiolect - my spoken speech, my habits of use and understanding of the meaning of words - is a constituted achievement based on my past history of speaking speech. Conversely, these acquired habits and understanding will inform and constrain any new efforts of expression and understanding I might undertake. By extension, in order to accrete to the collective system of meaningful language, that is, in order to be a formative instance of speech for the language at large, speaking speech must have first been taken up into the configuration of spoken speech of some individual. Once it has sedimented to the level of an intersubjective acquisition, however, spoken speech constrains what it is possible to communicate within the historically situated linguistic system. What I can say in the English language depends on a historically constituted, shared system of spoken speech.

Further clarifying such relationships is a challenging task for philosophy of language and linguistics, touching on questions concerning the relationship between idiolects and dialects, pragmatics and semantics, and speaker and expression meaning that remain contentious today. Phenomenology of Perception moves in the orbit of these issues, though often without clearly delineating them as such. Merleau-Ponty's views on these matters will take on increased clarity when he encounters Saussure and begins his transformative appropriation of structuralism into phenomenology. However, we can gain further insight concerning his later views on the matter by clarifying his initial position in Phenomenology of Perception concerning the relation between speaking and spoken speech as it can be found implicit in that text on the most charitable reading.

\section{Two Kinds of Speech?}

With these further clarifications in mind, let us return now to the question of how to best understand the distinction between speaking and spoken speech. We saw that there is some textual support, and some exegetical precedent, for interpreting Merleau-Ponty as holding that this is a distinction between different kinds of speech event: there are those incidences of speech that are genuinely expressive in an originary sense, constituting new meaning for individuals or traditions; and there are those incidences that only draw upon the resources of already constituted meanings. However, this tidy distinction is complicated at once for reasons we have already seen. For even the speaking speech of the most innovative of authors and philosophers always achieves its expressive function within the context of spoken speech. To the extent that it manages to transform this whole, it is not so much creation of meaning ex nihilo as it is a "coherent deformation" of the whole. ${ }^{13}$ As for the speaking speech of the

\footnotetext{
${ }^{13}$ I here borrow a notion from Merleau-Ponty's later work, though one that is already implicit in PhP. See especially the essay "Indirect Language and the Voices of Silence" (Merleau-Ponty 1964b, 54f., 81).
} 
child uttering its first word, this originary speech, too, is constrained and conditioned by an existing context of spoken speech. In fact, it is doubly constrained: on the one hand, it is constrained by the existing intersubjective structures and conventions of spoken speech, the linguistic world that the child will take on through acquisition; and, on the other, it is conditioned by an existing set of acquired skills and communicative experiences that the child has already acquired by the time it will utter its first word, the existing nexus of pre-, proto-, and para-linguistic meaning within which linguistic meaning will establish itself. If we accept Merleau-Ponty's view of the continuity of verbal speech with sub-verbal, bodily understanding, expression, and communication, then this background of habits and understanding also deserves to be called spoken speech for the child in an extended sense.

It appears, then, that spoken speech, in both the individual and collective senses, is always implied as the background against which speaking speech unfolds. Thus, if we want to maintain the distinction between speaking and spoken speech as a distinction of kind, "speaking speech" will just designate that subset of speech events that, operating on the basis of spoken speech, achieve a creative effect with respect to an existing idiolect and dialect, while "spoken speech," in a narrow sense, will designate that subset of speech events that do not achieve any such creative effect. But now we must ask how we will distinguish phenomenologically between incidences of speaking and spoken speech, thus understood. One way to approach this issue - further developing one of Merleau-Ponty's favorite examples - is to ask, when does the process of language acquisition generally, or the learning of an individual word more specifically, come to an end? If we grant that acquisition is a creative process for the learner, one during which new meanings are being formed and laid down to constitute sedimented, spoken speech, when does this process reach completion? As Merleau-Ponty himself would later remark, it would be an error to ascribe anything like a full-blown adult understanding of the meaning of a word to a child uttering its first word (Merleau-Ponty 1973a, 15-19). So then, how many times must the child speak the first word and hear it spoken before it achieves its final, acquired, sedimented form? And how much complementary understanding of the world, of comparable and contrasting terms and concepts, and of communicative and expressive practice in general, must also fall into place before this one sign and its signification has been securely locked down once and for all? Indeed, when does this process begin? For if we grant the gestural theory of speech's claim that there is continuity between pre-verbal, bodily expression and verbal, more narrowly linguistic speech, at what moment can we say that the child begins to learn "speech"? The "first word" may be cause for celebration and great pride for parents, but it is not clear that it marks as decisive a moment in the child's expressive development. ${ }^{14}$

From the perspective of Merleau-Ponty's phenomenology, there is no definitive beginning or end to acquisition. Rather, "far from being limited to the first years, language acquisition is coextensive with the very exercise of language" (Merleau-Ponty 1973a, 53). This is so in part, as we shall see, because there is no determinate and final "language" to acquire in the first place. ${ }^{15}$ Thus, it is perhaps better to

\footnotetext{
${ }^{14}$ We now know that children already begin to acquire the cadences and rhythms of their maternal tongue while still in the womb. We are spoken to before we enter into the world, just as we continue to speak from beyond the grave in writing and memory. Viewed phenomenologically, these would be the vague boundaries of the speaking subject's career of expressive speech, in contrast to the much more narrowly defined "critical window" of neurological receptivity for language acquisition.

${ }^{15}$ Merleau-Ponty would be pleased to see this insight confirmed in recent work on language that seeks to grasp a more intimate relation between language as a temporal phenomenon and language as a static system. Reacting against generativist dogmas, in much the same way that the later Merleau-Ponty can be seen as opposing structuralist dogmas, Christiansen and Chater maintain that "by considering the cascade of processes that led
} 
follow Merleau-Ponty's implied suggestion from the Phenomenology of Perception and refer to language learning as an ongoing process of "assumption" - taking up, taking over, taking on, and taking to language, while being taken in by it - rather than one of "acquisition," with its connotations of proprietariness and finality. ${ }^{16}$ Consider how Merleau-Ponty describes the relationship between acquired thoughts and present thinking (bearing in mind that for Merleau-Ponty, thinking is internally related to speaking and language, and thus that the description applies equally to present and acquired speech):

My acquired thoughts are not an absolute acquisition; they feed off my present thought at each moment; they offer me a sense, but this is a sense that I reflect back to them. In fact, the acquisition that is available to us expresses, at each moment, the energy of our present consciousness. Sometimes it becomes weaker, such as happens with fatigue, and then my "world" of thought becomes impoverished and is reduced even to one or two obsessive ideas; sometimes, on the contrary, I am directed toward all of my thoughts, and each word that is spoken in front of me thus engenders questions or ideas, regroups and reorganizes the mental panorama, and appears with a precise physiognomy. The acquired, then, is only truly acquired if it is taken up in a new movement of thought, and a thought is only situated if it itself assumes its situation. (PhP 163/132)

Present speech and understanding always occurs against a background of sedimented speech and thought. But conversely, it never merely says the "same thing," is never mere dependence on something already spoken, but always involves some degree of creativity in taking up and reshaping what has already been laid down. We cannot absolutely distinguish between speech experiences in which a "new" signification comes about for me and those in which this creative dimension is absent. Rather, we can at best roughly distinguish the degree to which my present speech experience is restructuring my acquired, spoken speech.

Much the same point concerning the interminable nature of acquisition emerges from considering Merleau-Ponty's contextualist understanding of how a word comes to be charged with the meaning it has for me:

Communication certainly presupposes a system of correspondences, such as those given by the dictionary, but it goes beyond, and it is the sentence that gives each word its sense, it is for having been employed in different contexts that the word gradually takes on a sense that is impossible to fix absolutely. ${ }^{17}$ (PhP 448/408)

Every new occurrence of a word that I produce or encounter contributes to the sense that that word takes on for me - a sense that is ever in flux and that can only ever achieve a relative stability. All speech

language to come to be, we can perhaps better understand what language is" (Christiansen and Chater 2016, xi). They contend that there is no strict distinction to be drawn between acquisition and processing, since acquisition is ongoing and consists of innumerable attempts at processing individual utterances (11). More generally, I believe that Merleau-Ponty would have been in favor of the usage-based approach that these authors champion (following, e.g., Tomasello 2003), seeing in it a plausible middle ground between intellectualist and behaviorist extremes.

${ }^{16}$ Perhaps this is why Merleau-Ponty puts the verb "acquérir" in scare quotes when discussing word-learning (PhP 449/409). Later in the same chapter, he will stress that consciousness does not "constitute" language, but rather "assumes" it (PhP 464/424). The verb "assumer" is often rendered as "to take up" in Landes' translation of PhP.

${ }^{17} \mathrm{PhP}$ 448/408. On the contextualism of word-learning, see PhP 219/184, 464f./425. 
is speaking speech, insofar as it inserts itself into and partially draws its meaning from a context that is never strictly the same as past contexts. Even the simple act of identifying an object requires an element of creativity, insofar as it establishes an identity within the constant change of time. Every reiteration is in fact a reappropriation within a new context. Only the machine ever says "the same thing" - precisely because the machine says nothing at all.

The continuous nature of acquisition and the contextuality of meaning entail that the categorization of any given speech event as an incidence of either speaking or spoken speech - i.e., applying a distinction between kinds of speech events - can only ever be relative and tentative. For the degree to which an isolated speech event is formative with respect to one's understanding of the meaning of the terms and phenomena in question may vary from speaker to speaker, listener to listener. Weighty words that are lost on one listener may be revelatory for another. So too, for one and the same individual, words that once seemed insignificant may later come to take on a profound meaning. It may only be years later, as they echo in memory, that the words of a past lover take on their full consequence. Historically, the untimely works of a philosopher or artist may lie dormant for decades before a public arrives that can properly assume them and make sense of them. The broader point that emerges from such examples is that the attempt to isolate speech into separable units (whether the unit be the bodily gesture, the speech act, or the work of art) and sort these units into the categories of creative and derivative risks falsifying the intersubjective relationality, the temporality, and, indeed, the holistic mereology of speech. What Merleau-Ponty has to say concerning the cohesion and continuity of experience in general against the atomizing approach in phenomenology and psychology applies equally to our understanding of speech: just as there are no "distinct acts of consciousness" in a life, and no isolated things in the world, so too, strictly speaking there are no isolated acts of speech. ${ }^{18}$

For these reasons, following the passage quoted above, Merleau-Ponty refers to the distinction between the sedimented and the spontaneous, the acquired and the present, as a distinction between two moments of experience. ${ }^{19}$ Or, to introduce a term he will use elsewhere, instituted language is a field, or dimension informing the meaning of my current speech. ${ }^{20}$ In spite of how he occasionally states the distinction in the Phenomenology of Perception - particularly in the two footnotes, discussed in the previous section, in which the distinction is explicitly introduced - this is how I propose we understand the distinction, rather than as a distinction between two kinds of speech event. When Merleau-Ponty directs our attention to the creative speech of the child, the nomothete, the lover, and the philosopher, we should take these cases as exemplary of speaking speech, because in them, speaking speech - the

\footnotetext{
${ }^{18} \mathrm{Cf}$. PhP 468f./429f.: "In a sense, there are no more distinct acts of consciousness or of Erlebnisse in a life than there are isolated things in the world. Likewise, as we have seen, when I move around an object, I do not obtain a series of perspectival views that I subsequently coordinate through the idea of a unique geometrical plan (all I find is a bit of 'indeterminacy' [bougé] in the thing that crosses through time all by itself), so too am I not a series of psychical acts, nor for that matter a central I who gathers them together in a synthetic unity, but rather a single experience that is inseparable from itself, a single 'cohesion of life,' a single temporality that unfolds itself [s'explicite] from its birth and confirms this birth in each present."

${ }^{19}$ Indeed, he states that this is the structure of the world itself: "The structure 'world,' with its double moment of sedimentation and spontaneity, is at the center of consciousness" (PhP 163/132). Here we must not let the image of sedimentation mislead us into thinking that what is acquired has been fossilized, that spoken speech has been written in stone, as it were. Spoken speech continues to speak, dynamically interacting with and responding to speaking speech.

${ }^{20}$ Cf. PhP 222f./188, 453/413; Merleau-Ponty 2001, 44.
} 
creative, expressive aspect of speech - is especially salient. Studying these cases thus allows us to get the phenomenon of speaking speech most clearly in view. That does not imply, however, that speaking speech is restricted to such cases. It is rather an ubiquitous phenomenon, an aspect of all speech rather than a rare occurrence. The unfamiliar limit cases are introduced to illuminate something about the normal cases that is concealed to us by the familiarity of the latter.

\section{A Question of Priorities}

Having clarified the distinction between speaking and spoken speech as one between different moments, aspects, or dimensions of expressive experience, rather than between kinds of speech, we can now obtain a clearer understanding of the relationship that holds between the two. Every new speech event both presupposes the background of sedimented, acquired speech and contributes to the shaping and reshaping of that background. The habits of thought, perception, and action that were laid down through past expression condition, without fully determining, the way in which I take up new situations, and the possibilities for new speech within them. However, that new speech will invariably exert some degree of creative influence on the whole of my acquired field of significance. That restructuring will be more radical in cases of learning novel words and concepts requiring accommodation, or of genuine engagement, productive or receptive, with art. Though it will be less radical in more routine cases of expression, such as in Heideggerian Gerede, it will never be completely absent. For the paradoxical intertwining of speaking and spoken, the novel and the established, the constituting and the constituted, is what characterizes the dynamic structure of speech as such, and not just one particular kind of speech:

Speech is this paradoxical operation in which - by means of words whose sense is given and by means of already available significations - we attempt to catch up with an intention that in principle goes beyond them and modifies them in the final analysis, itself establishing the sense of the words by which it establishes itself. ${ }^{21}$

This characterization seems to lend support to the view that the relationship between speaking and spoken speech is one of interdependence. ${ }^{22}$ Those who hold this interpretation see themselves as contradicting Merleau-Ponty's own suggestions that there is a primacy of "primary," "authentic," "transcendental," or "originary" speech, that is, of speaking speech over spoken speech. However, it could be that the interdependence view is correct within one domain and false within another, thus dissolving the apparent contradiction. Returning to the fourfold distinction I introduced above, I want to suggest that the interdependence view is correct concerning the relation of speaking and spoken speech

\footnotetext{
${ }^{21} \mathrm{PhP} 449 / 408 \mathrm{f}$. The passage is from the chapter on the Cogito, in Part III of PhP. This understanding of the speaking and the spoken as intertwined structural moments of all speech, rather than as opposed kinds of speech, emerges much more clearly in the later parts of $\mathrm{PhP}$ than it does in the chapter from Part I that introduces the distinction. This could be because Merleau-Ponty was working out and clarifying his views on the topic as he was writing the book and left some inconsistencies in earlier chapter. Or it could belong to the book's dialectical method of presentation. In any event, I believe the exegesis presented here lends support to Hass' contention $(2008,148)$ that the notion of expression, if somewhat flawed in early chapters of PhP, is brought to fruition by Part III. This interpretation runs counter to Barbaras' view (2004) that it is only in later works that Merleau-Ponty achieves an adequate grasp of expression, and that this constitutes a decisive break with his early work.

${ }^{22}$ This is the dominant interpretation in the literature. See Baldwin 2007; Hass 2008; Inkpin 2016.
} 
for the individual. However, there remains a question of how the speaking and spoken speech of the individual relate to the language as such, conceived as the intersubjectively constituted system of conventions governing the meanings and use of terms. Can we still ascribe priority to the speech of the individual here, or is individual speech rather merely an instantiation of the universal idealities accessible to all? And does each individual speech event continue to exercise a formative, "speaking" function with respect to the collective whole of spoken speech, the way I have argued it does with respect to the individual's idiolect?

"The language itself" often appears to have a certain autonomy vis-à-vis any individual speaker. I may be a competent speaker of English, but the fact that "dog" means dog in English seems to hold independently of my beliefs and usage of the word. Two of Merleau-Ponty's most important interlocutors in his later work, the later Heidegger and de Saussure, maintain the priority of the impersonal body of "language" (la langue in Saussure as opposed to la parole, die Sprache in Heidegger as opposed to das menschliche Sprechen). Language speaks ("die Sprache spricht"), and human beings speak only insofar as they "enspeak," or (cor)respond to (entsprechen), this original speaking of language itself (Heidegger 1985, 30; 1971, 210). Or, as Heidegger also put the point, quoting Novalis, "the peculiar property of language" is that "language is concerned exclusively with itself" (Heidegger 1985, 229; 1982, 111).

There is something right in this, even on Merleau-Ponty's view. He too is tempted by such formulations. ${ }^{23}$ But by restoring, against both intellectualism and empiricism, the speaking subject to the center of the phenomena of speech and language (PhP 214/180), Merleau-Ponty is able to marshal a quite elementary consideration against the Heideggerian view. Even if there is some truth in stating that human being speaks only by bringing language to speech, by enspeaking it, the converse is equally true: language only speaks insofar as human being speaks it. Merleau-Ponty can rely on a thoroughly naturalistic line of reasoning here, the likes of which is not permitted in Heidegger's thought but entirely respectable for Merleau-Ponty: there was no language (understood as an ideal, cultural achievement) before human being spoke; there will be none should human being ever once and for all cease to speak; and language only speaks now because human being assumes it, in the sense discussed earlier of taking up the past achievements that have accreted in individual and collective linguistic repositories. For Merleau-Ponty, this holds true even for the vaunted mathematical idealities:

What we call an "idea" is necessarily linked to an act of expression and owes its appearance of autonomy to this act. It is a cultural object, like the church, the street, the pencil, or the Ninth Symphony. [...] the idea of the triangle along with its properties and the idea of the quadratic equation have their historical and geographical regions, and if the tradition from which we

\footnotetext{
${ }^{23}$ See PhP 229/194: "[I]f we push the research far enough, we find that language itself, in the end, says nothing other than itself, or that its sense is not separable from it. We must, then, seek the first hints of language in the emotional gesticulation by which man superimposes upon the given world the world according to man" (italics mine). However, in The Visible and the Invisible, Merleau-Ponty writes that "it is the error of the semantic philosophies to close up language as if it spoke only of itself: language lives only from silence; everything we cast to the others has germinated in this great mute land which we never leave" (Merleau-Ponty 1969, 126). A comprehensive exposition might show the opposition between these passages to be merely apparent. See also Merleau-Ponty 1973b, 102f, 115.; 2003, 87.
} 
receive them and the cultural instruments that carry them were destroyed, then new acts of creative expression would be necessary to bring them into the world. (PhP 450/410)

What was missing from our previous formulation - "'dog' means dog in English" - was an essential qualification: "'dog' means dog in English because those who speak English assume their language and world accordingly." Here, Merleau-Ponty can critique Heidegger for risking mistaking the anonymity of our intersubjectively constituted idealities for their autonomy, for an independence from all subjectivity. To the extent that it is true, "language speaks" is an elliptical utterance. Language speaks because we hear in it the echoes of the speech of our fellow speaking subjects - and because we respond to and assume this speech. ${ }^{24}$ Yes, "language speaks" (Merleau-Ponty 1973, 102). But, in the end, "that which we call language is nothing but the visible result and recording [...] of the power that speaking subjects have to go beyond signs towards their meaning." ${ }^{25}$

In this respect, it is with language as with tools: a hammer is only a hammer in light of subjects who take it up as a hammer in hammering. Language is only language insofar as it is taken up by subjects who speak it. ${ }^{26}$ That is not to say that, once taken up, our tools do not mark us indelibly. The world and body of a visually impaired person are permeated through and through by the cane and the domain of possible perception and action that it opens, just as the worlds and bodies of the violinist and carpenter are infused with the expressive possibilities of their respective instruments and behaviors. So too, for those who speak, language comes to be inscribed into the very fabric of our worlds. Word becomes flesh. But it does so not as a sedimentation deposited from on high, as it were, or as a Geschick des Seins, but rather as the enduring trace of a body's proper, originally expressive activity. As with all other expressed cultural idealities, language has its basis in the human body as the original locus of all expression: "our body is not merely one expressive space among all others," but rather it is "the origin of all the others, it is the very movement of expression" (PhP 182/147).

We saw above that it was instructive to question Merleau-Ponty's claims to a primacy of speaking speech with respect to spoken speech so far as the individual is concerned. Speaking and spoken speech are always equally involved in an internal tension wherever there is expression, and there is thus a mutual interdependence that holds between them. This is an interdependence in the domain of significance, as it were, a mutual conditioning of present expression and its past achievements. However, in another sense, given the ontological primacy of the expressive body as the "condition of the possibility [...] of all the acquisitions that constitute the cultural world" (PhP 448/406), we can assert that

\footnotetext{
${ }^{24}$ This formulation of Merleau-Ponty's position recalls Levinas' view on the centrality of language in ethics and our relation to the other. Indeed, Levinas' distinction $(1969,1998)$ between saying (dire) and said (dit) appears to parallel, and was perhaps inspired by, Merleau-Ponty's distinction between speaking and spoken speech. With his emphasis on the essentially intersubjective, intercorporeal dimension on language, it may be that the seeds of an ethics are germinating in Merleau-Ponty's discussions of speech and acquisition - a further point of demarcation from Heidegger's view on language.

${ }^{25}$ Merleau-Ponty 1973, 103. It may be that written language is responsible for instilling in us the prejudice that the meanings of language are imperishable. As Merleau-Ponty observers (commenting on Husserl's "Origin of Geometry"), "It is writing which once and for all translates the meaning of spoken words into ideal being [...] evoking a total speech" (Merleau-Ponty 1988, 187).

${ }^{26}$ Cf. Merleau-Ponty's comment on the subsistence of language in the essay "The Metaphysical in Man": "That general spirit which we all constitute by living our life in common, that intention already deposited in the given system of the language [...] only subsists on the condition of being taken up or assumed by speaking subjects and lives on their desire for communication" (Merleau-Ponty 1964a, 88).
} 
there is indeed a primacy of speech with respect to the language as such, understood as a cultural ideality. This is an ontological priority, we might say, of the real over the ideal, of the concrete, constituting act of expression over the abstract, constituted system of conventional significations. This insight that language is only insofar as it is assumed highlights another aspect of speaking speech's achievement, namely, its role in re-creating, or sustaining the articulated constellation of significations that is an intersubjectively shared language. ${ }^{27}$ Language as a cultural product is not only in need of an original institution and constitution, but requires further to be continuously reinstituted and reconstituted. Every act of speech, even if it does not create a noticeable shift in meaning, plays at least this minimal role of sustaining these metastable cultural idealities, which, as we have seen, have no existence but the one we breathe into them. ${ }^{28}$ This re-creative role is an essential achievement of speaking speech that we miss if we accept those interpretations that take speaking speech as a type of speech event, and limit it to those rare cases of creative expression, in the narrow sense, that engender radically new meanings or dramatic transformations in the existing constellations of meaning. ${ }^{29,30}$

Extending a line of reasoning that Merleau-Ponty has already developed in Phenomenology of Perception, we might say that the error that leads us to believe in the autonomous reality of the world of established linguistic significations is a prejudice parallel to our unquestioned belief in the existence of the perceptual world. ${ }^{31}$ Where perception is concerned, "objective thought" - the thought of common sense and science (PhP 100/74) - leads us to forget the phenomenal process of perception in favor of the world of objects that are in fact the constitutive achievement of this process. We take as primary, as really real, the constituted external world of spatio-temporal objectivities. But from the perspective of a phenomenological ontology, such objectivities are secondary to the phenomenal process of perception. Now, an analogous process to this "dialectic by which perception hides itself from itself" (PhP 85/59) is played out on the level of speech and language. If it belongs to "the essence of consciousness to forget its own phenomena and to thus make possible the constitution of 'things'," it is

\footnotetext{
${ }^{27}$ Cf. PhP 239/203.

${ }^{28}$ On Merleau-Ponty's conception of language as a sort of metastable equilibrium, see Landes 2017.

${ }^{29}$ Inkpin 2016, 109f. identifies two arguments in Merleau-Ponty's texts for the priority of speaking speech over spoken speech, an argument from genetic priority and an argument from new meaning, and finds neither convincing. I propose that the above argument from ontological dependency and the need for the ideal to be sustained is Merleau-Ponty's strongest argument for the priority claim, and articulating it helps to clarify the proper sense of that claim.

${ }^{30}$ It may be that, just as there can be a greater or lesser degree of creativity in any instance of speaking speech, so to the degree of re-creativity might be greater or lesser in any given speech act. For example, borrowing Husserl's terminology, it could be that fulfilled instances of speech - such as "look at that dog!" accompanied by a pointing gesture and the perception of an actual dog - do more to sustain the domain of constituted significations for concrete terms such as "dog" than do unfulfilled acts of speech ("Has anyone seen my dog?"). Heidegger's idle talk (Gerede) might serve as a minimal threshold, speech in which both the creative and re-creative aspects of speaking speech are at their absolute minima. Or perhaps in automatic speech, the re-creative value is truly zero, as Merleau-Ponty suggests is the case for aphasics who are capable only of the most routine and automated linguistic expression (Merleau-Ponty 2010, 363). In any event, we have here once again a rich continuum of cases rather than distinct kinds of speech act.

31 "Le préjugé du monde" (PhP 27/5).
} 
likewise the essence of speech to forget its own expressive function and thus make possible the constitution of "meanings," of language as a cultural ideality. ${ }^{32}$

For his part, Saussure seems to acknowledge this priority of the speaking subject, granting that "a language [langue] is not an entity, and exists only in its users." ${ }^{13}$ And yet, what he grants with one hand, he takes back with the other. For he also insists that la langue, the structured language system, "as distinct from speech [parole], is an object that may be studied independently" (14). He is able to maintain this seemingly contradictory position because la langue is quite literally in its users, being ultimately a neurobiological reality that can be localized in the brains of the speakers of the language, where la langue is instantiated as a system of associated sound patterns and concepts (12-15). ${ }^{34}$ According to this proposal, if we could construct a composite image of the relevant brain areas of all of the speakers of a particular language, we would effectively be looking at la langue. Isolated in this way, the object of linguistic inquiry can be treated synchronically, extracted from the temporal, diachronic processes of language assumption (use, acquisition, and historical and biological evolution), while still being deemed just as "real" as speech.

But to identify language with an objective reality in the world such as the brain is to rupture completely its internal relation to the fundamentally subjective processes of speaking and expression. MerleauPonty did not study Saussure until after publishing the Phenomenology of Perception. When he did, one of the first tasks for him was to critique Saussure's overly tidy distinctions and his extraction of la langue from the temporality and subjectivity of speech. "One cannot absolutely distinguish language from the speaking subject," he remarks with respect to Saussure in his 1949-50 lectures on Consciousness and the Acquisition of Language (Merleau-Ponty 1973a, 99). Similarly, the Saussurean notion of a stark contrast between diachronic and synchronic aspects - a sort of attempt to sever the internally related moments of speaking and spoken speech - must be revised. La langue, Merleau-Ponty observes, "would not be a Gestalt of the moment, but a Gestalt in movement" (1973a, 100), a "moving equilibrium," a system that "never exists wholly in act but always involves latent or incubating changes" (Merleau-Ponty 1964, 87). It is because of his original account of the phenomena of expression and speaking speech in the Phenomenology of Perception that Merleau-Ponty is able to achieve a fruitful appropriation of structuralism within phenomenology when he does encounter Saussure, rather than treating the two

\footnotetext{
32 Merleau-Ponty himself describes the process in such analogical terms in PhP, though he never explicitly draws attention to the parallel between the two cases. See, e.g., PhP 462/422: "The wonder of language is that it makes itself forgotten. [...] The expression fades away in the face of the expressed, and this is why its role as mediator can pass by unnoticed[.]"

Further, parallel to the distinction between primary and secondary speech, Merleau-Ponty offers a distinction between primary and secondary perception (PhP 69/46). Here there is a parallel risk of understanding this as a distinction between types of perception rather than dimensions of perception. Unlike the case of speaking and spoken speech, in the case of perception, Merleau-Ponty is alert to and quick to dispel the deceptive interpretation: "[E]ach perception - and not merely perceptions of scenes that I discover for the first time - begins anew for itself the birth of intelligence and has something of an inspired invention to it" (PhP 69/47).

33 de Saussure 1983, 5. I here refer only to the Saussure of the originally published Course in General Linguistics. As Beata Stawarska has argued, another, more phenomenological Saussure is documented elsewhere. See Stawarska 2015.

${ }^{34}$ This is a view that has been taken up by Chomsky and his followers, but one that Merleau-Ponty and most of his contemporary enactivist and phenomenological successors would deny.
} 
movements as intrinsically opposed, as has often been assumed. ${ }^{35}$ The same can be said for his encounter with Heidegger's later thought.

\section{Conclusion}

We began by considering Merleau-Ponty's distinction between speaking and spoken speech, taking this tentatively as a distinction between two kinds of speech event. We found that such a distinction can only be relative, and that the speaking and spoken aspects of speech are present in all speech. At best, one could perhaps sort acts of speech according to their greater or lesser degree of formative novelty with respect to the existing system of sedimented meanings, to the extent that it is possible to do this at any moment in time while ignoring the intrinsic temporality of language. However, all speech events take up and contribute to the shaping of spoken speech, and thus the more basic distinction is between speaking and spoken speech as two interlocking aspects, or dimensions, of all speech. Further, even when a new speech event does not exert a palpably creative, transformative function on the existing configuration of signification, all speech at least exercises the re-creative function of perpetuating the meta-stable idealities of the established language. These do not enjoy a sustained existence apart from being taken up ever anew by speaking subjects, and they are thus ontologically dependent on this process of language assumption.

Clarifying Merleau-Ponty's views on this central theme in his philosophy helps focus the originality of his position in the landscape of $20^{\text {th }}$ century views on language, as I have suggested above in juxtaposing his position with those of the later Heidegger and Saussure. Further, we have seen that the phenomenon of speaking speech has both a breadth and latent tensions and ambiguities that Merleau-Ponty may not have fully appreciated at the time of Phenomenology of Perception. Seeing these potentials and tensions germinating in that work helps us understand the ensuing trajectory of his thought, as the notion of expression takes on an increasingly central role in his work, with ramifications for all areas of his philosophy dilating from ontology outward.

Indeed, Merleau-Ponty's discussion of the intertwining of speaking and spoken speech can be seen as emblematic for, perhaps even as epitomizing, the broader dialectic of passivity and activity within experience. What Merleau-Ponty writes of passivity in Phenomenology of Perception could equally characterize spoken speech as I have attempted to elucidate it: Passivity is "being encompassed, a situated being - prior to which we do not exist - that we perpetually start over and that is constitutive of us." ${ }^{36}$ And, just like speaking and spoken speech, activity and passivity can only be understood beginning with their originary dialectical interrelation, not by conceiving them as externally related terms. It is no accident that, as Merleau-Ponty continued to struggle to determine this original mediacy, the master terms of his philosophy - perception and body, expression and flesh, affectivity and temporality, chiasm, reversibility, and entrelacement ${ }^{37}$ - increasingly came to be determined through their internal relation to one another.

\footnotetext{
${ }^{35}$ For more on this unfortunate assumption, see Stawarska 2015.

${ }^{36} \mathrm{PhP}$ 490/451. Cf. Hughes 2013.

${ }^{37}$ In addition to The Visible and the Invisible (Merleau-Ponty 1969), see Merleau-Ponty's late lecture course on Husserl's Origin of Geometry, published in Husserl at the Limits of Phenomenology (Merleau-Ponty 2001). See also Lawlor 2001, 2002.
} 
But the importance of these inquiries extends beyond debates in phenomenology, continental philosophy, or Merleau-Ponty studies more narrowly. With the distinction between speaking and spoken speech, Merleau-Ponty identifies an omnipresent linguistic phenomenon, but one that conceals itself from both common sense and theoretical reflection on language. He provides a principled, phenomenological account of how this self-concealment occurs, of how we tend to blind ourselves to the very nature of language and our role in its constitution and perpetuation. As such, his claim is of significance for philosophy of language more generally. One of the greatest challenges confronting recent phenomenological approaches to language is establishing what consequences, if any, these contributions have for the more dominant tradition of philosophy of language. ${ }^{38}$ One place to start would be to work out the consequences that Merleau-Ponty's account of speaking and spoken speech would have for contentious issues in contemporary philosophy of language, such as the relation between speaker and expression meaning, the relation between semantics and pragmatics, the role of context in establishing meaning, and the ontology of language more generally. Developing these lines of thought depends first of all upon clearly articulating the distinction between speaking and spoken speech, which has been the principle purpose of the present effort.

${ }^{38}$ See Engelland 2014; Romano 2015; Inkpin 2016; Taylor 2016; Hatab 2017. 


\section{Bibliography}

Baldwin, Thomas. 2007. "Speaking and Spoken Speech." In Reading Merleau-Ponty: On Phenomenology of Perception, edited by Thomas Baldwin. Routledge.

Barbaras, Renaud. 2004. The Being of the Phenomenon: Merleau-Ponty's Ontology. Indiana University Press.

Christiansen, Morten, and Nick Chater. 2016. Creating Language: Integrating Evolution, Acquisition, and Processing. Cambridge, Mass: The MIT Press.

Engelland, Chad. 2014. Ostension: Word Learning and the Embodied Mind. Cambridge: The MIT Press.

Fóti, Véronique M. 2013. Tracing Expression in Merleau-Ponty: Aesthetics, Philosophy of Biology, and Ontology. Evanston: Northwestern University Press.

Hass, Lawrence. 2008. Merleau-Ponty's Philosophy. Bloomington: Indiana University Press.

Hatab, Lawrence J. 2017. Proto-Phenomenology and the Nature of Language: Dwelling in Speech I. Lanham: Rowman \& Littlefield International.

Heidegger, Martin. 1971. Poetry, Language, Thought. Translated by Albert Hofstadter. New York: Harper \& Row.

-- . 1982. On the Way to Language. Translated by Peter D. Hertz. New York: Harper \& Row.

-- - 1985. Unterwegs zur Sprache. Edited by Friedrich-Wilhelm von Herrmann. Gesamtausgabe 12. Frankfurt am Main: Vittorio Klostermann.

Husserl, Edmund. 1970. The Crisis of European Sciences and Transcendental Phenomenology: An Introduction to Phenomenological Philosophy. Translated by David Carr. Evanston: Northwestern University Press.

- - . 1973. Zur Phänomenologie Der Intersubjektivität. Texte Aus Dem Nachlass. Dritter Teil: 19291935. Edited by Iso Kern. Husserliana, XV. The Hague: Martinus Nijhoff.

-- - 1982. Ideas Pertaining to a Pure Phenomenology and to a Phenomenological Philosophy: First Book: General Introduction to a Pure Phenomenology. Translated by F. Kersten. The Hague: Springer.

- - . 1988. In Praise of Philosophy and Other Essays. Translated by John Wild, James M. Edie, and John O'Neill. Evanston: Northwestern University Press.

- - . 2001. Logical Investigations. Edited by Dermot Moran. Translated by J. N. Findlay. 2 vols. London: Routledge.

Hughes, Fiona. 2013. "A Passivity Prior to Passive and Active: Merleau-Ponty's Re-Reading of the Freudian Unconscious and Looking at Lascaux." Mind 122 (486):419-50.

Inkpin, Andrew. 2016. Disclosing the World: On the Phenomenology of Language. Cambridge: The MIT Press.

Landes, Donald. 2017. "Language and Development: Paradoxical Trajectories in Merleau-Ponty, Simondon, and Bergson." Phenomenology and the Cognitive Sciences 16 (4):597-607.

-- - 2013. Merleau-Ponty and the Paradoxes of Expression. New York: Bloomsbury.

Lawlor, Leonard. 2001. "Verflechtung: The Triple Significance of Merleau-Ponty's Course Notes on Husserl's 'The Origin of Geometry.'" In Merleau-Ponty 2001.

- - - 2002. "The Legacy of Husserl's 'Ursprung Der Geometrie': The Limits of Phenomenology in Merleau-Ponty and Derrida." In Merleau-Ponty's Reading of Husserl, edited by Ted Toadvine and Lester Embree, 201-23. Dordrecht: Kluwer.

Levinas, Emmanuel. 1969. Totality and Infinity: An Essay on Exteriority. Translated by Alphonso Lingis. Pittsburgh: Duquesne University Press.

-- - 1998. Otherwise than Being or Beyond Essence. Translated by Alphonso Lingis. Pittsburgh: Duquesne University Press. 
Merleau-Ponty, Maurice. 1964a. "The Metaphysical in Man." In Sense and Non-Sense, translated by Hubert L. Dreyfus and Patricia Allen Dreyfus, 83-98. Evanston: Northwestern University Press.

- - . 1964b. Signs. Translated by Richard McCleary. Evanston: Northwestern University Press.

- - . 1969. The Visible and the Invisible. Translated by Alphonso Lingis. Evanston: Northwestern University Press.

- - - 1973a. Consciousness and the Acquisition of Language. Translated by Hugh J. Silverman. Evanston: Northwestern University Press.

-- . 1973b. The Prose of the World. Translated by John O'Neil. Evanston: Northwestern University Press.

- - - 1976. Phénoménologie de la Perception. Paris: Gallimard.

- - . 2001. Husserl at the Limits of Phenomenology. Evanston: Northwestern University Press.

- - . 2002. Phenomenology of Perception. Translated by Colin Smith. London: Routledge.

- - . 2003. Nature: Course Notes from the Collège de France. Edited by Dominique Seglard. Translated by Robert Vallier. Evanston: Northwestern University Press.

- - . 2010. Child Psychology and Pedagogy: The Sorbonne Lectures 1949-1952. Translated by Talia Welsh. Evanston: Northwestern University Press.

- - . 2012. Phenomenology of Perception. Translated by Donald Landes. New York: Routledge.

Romano, Claude. 2015. At the Heart of Reason. Edited by Anthony J. Steinbock. Translated by Michael B. Smith. Evanston: Northwestern University Press.

Stawarska, Beata. 2015. Saussure's Philosophy of Language as Phenomenology: Undoing the Doctrine of the Course in General Linguistics. Oxford University Press.

Taylor, Charles. 2016. The Language Animal: The Full Shape of the Human Linguistic Capacity. Cambridge: Belknap Press.

Toadvine, Ted, and Lester Embree, eds. 2002. Merleau-Ponty's Reading of Husserl. Contributions to Phenomenology 45. Dordrecht: Springer.

Tomasello, Michael. 2003. Constructing a Language: A Usage-Based Theory of Language Acquisition. Cambridge: Harvard University Press.

Welton, Donn. 1983. The Origins of Meaning: A Critical Study of the Thresholds of Husserlian Phenomenology. The Hague: Martinus Nijhoff. 